\title{
Concrete Slab Comparison and Embodied Energy Optimization for Alternate Design and Construction Techniques
}

\author{
Dane Miller ${ }^{\mathrm{a}}$, Jeung-Hwan Doh ${ }^{\mathrm{b}^{*}}$, Mitchell Mulvey ${ }^{\mathrm{c}}$ \\ a,b,c Griffith School of Engineering, Griffith University, \\ Gold Coast Campus, Queensland 4222, Australia \\ *Corresponding author \\ E-mail address: J.doh@griffith.edu.au, Tel: +61 -7 555 29141, Fax: 61-7 55528065
}

\begin{abstract}
Construction material consumption is greater than any time in history. Australia produces approximately 30 million tonnes of finished building products each year, with over $56 \%$ of this quantity, by mass, being attributed to concrete and a further 6\%, steel. Globally, 23 trillion kilograms of concrete alone is consumed annually, with growing population driving increasing demands. This study assesses the environmental performance of various concrete slab systems. Historically, the focus of environmental performance in buildings has been Operation Energy (OE) requirements, however Zero Energy Buildings (ZEB) are changing this. Specifically the study investigates the environmental performance of concrete structures varying design parameters and construction techniques to optimise its Embodied Energy (EE). These structures are designed in accordance with all relevant Australian codes and standards. The various slab systems investigated include: beam \& slab, flat slab and flat plates while concurrently considering the use of conventionally reinforced and post-tensioned construction methods. Designs were compared in terms of EE outcomes given fixed design criteria, with results indicating reductions between $23.7 \%$ and $49.1 \%$ when utilizing post-tensioned construction methods.
\end{abstract}

Keywords: Optimization; Sustainable Structural Design; Slab Construction Techniques; Embodied Energy 


\section{INTRODUCTION}

The requirement for and pressure on increasing the adoption of sustainable alternatives has been well published and persistently discussed [1-5]. Global population growth is predicted to continue through the first half of this century to approximately 8.9 billion by 2050 [6]. The impacts of increased demand, due to population pressures, have led to the built environment being identified as the largest single anthropogenic contributor to climate change $[3,7]$. Given this, and the associated environmental impacts, the emphasis on the need to mitigate these cannot be over stated.

The construction, operation and maintenance of buildings are estimated to account for 40 $50 \%$ of all energy usage and anthropogenic GHG emissions globally [7-16]. Material usage continues to expand with over 23 trillion kilograms of concrete consumed annually $[17,18]$. Studies have identified the cement industry alone contributes more than 5\% of global anthropogenic $\mathrm{CO}_{2}$ emissions [19]. In Australia, in order to keep pace with growing demand, approximately 30 million tonnes of finished building products are produced each year. Over $56 \%$ of this quantity, by mass, is attributed to concrete and a further $6 \%$, steel [20]. In the US, the development industry consumes over $40 \%$ of all raw stone, gravel and sand material, $25 \%$ of all raw timber, $40 \%$ of energy and $16 \%$ of water annually [21, 22].

Conceptually, Sustainable Development (SD) is idyllic; delivering development by any definition that appropriately and equally benefits economic and social considerations, while concurrently minimizing related environmental impacts. SD has however also been described as: “a contradiction in terms” [23], "another development truism” [24], “elusive” [25], "an oxymoron" [26], and "creatively ambiguous" [27]. In the broad sense of the term, these descriptions are understandable. Specifically, sustainability can, and should, be more appropriately considered for any given product, service or process. In any context this is 
taking appropriate consideration of economic, social and environmental matters $[1,2,4,28$, 29].

In the building industry, sustainability considerations are poorly measured. Buildings inherently provide extensive social and economic benefits. The construction industry has been referred to as the lifeblood of the economy across the developed world and as such, satisfaction of the economic component is unquestioned [30, 31]. In the United States the construction industry is valued at over $\$ 1$ trillion and provides critical infrastructure to support industries while creating over 6.5 million jobs [22]. In Europe it is the industry to provide the largest single contribution to employment with over $7.5 \%$ of all employment, 9.7\% of the GDP and 47.6\% of the gross fixed capital formation in 1999 [32]. In Australia, the construction industry for $2008 / 2009$ was valued at $\$ 151.3$ billion, contributing $7.0 \%$ of GDP and employing 9.1\% of our workforce making it the fourth largest industry [33]. Similarly the social benefits are also extensive, providing: good quality indoor living environments; structural integrity; low vibration; a high degree of weather protection; high fire resistance; good thermal resistance and sound acoustic performance [34]. The environmental performance of buildings however, has proved more difficult to assess [35], however they have been identified to be environmentally evaluated, within the life cycle context [16, 36-38].

There presently exists a focus of environmental performance of a structure on the OE phase of a buildings life cycle compared with $\mathrm{EE}[39,40]$. The OE requirements are increasingly negated by the emergence of ZEB. A number of studies are beginning to appear in the development of these ZEB [41-44]. If achieved, the contribution of the OE phase would be removed entirely resulting in a major shift in assessing the environmental performance of structures. Previous research has highlighted the variability observed in published EE values, with this resulting in structural engineers being faced with contradictory information [40]. 
Many practitioners are confused as to the appropriate context with which to consider the incorporation of environmentally efficient structural elements into a design. Several sources place varying degrees of importance on different aspects of the design process [12, 40, 4447]. The outcome is an industry through which the inclusions of environmentally efficient structural elements are considered ancillary to other building design matters with structural engineers playing a limited role in the overall sustainability of a design [40,48]. The focus on OE requirements in a structures life cycle makes it not practical to predict the effect of a structural design decision on environmental performance $[49,50]$. These attitudes appear to be slowly changing however, with many studies presenting the possible importance of the initial investment in EE and design decisions on life cycle environmental performance [16, $39,40,51]$.

Globally, mechanisms have been developed in recent times to assist in the adoption of more sustainable buildings. Green Building assessment systems, under numerous different labels, broadly aim to quantify the sustainability attributes of structures. While there is merit in the application of these systems, the focus remains on OE requirements of a buildings life cycle contributions to sustainability. From a structural design perspective, there exists a gap through which improvements in the assessment of EE contributions and the acknowledgement of sustainable design is rewarded appropriately [40]. Variability in the assessment of environmental structural design performance is related to two key issues: 1) the variability in published, reliable EE data and 2) the willingness of the industry to develop, quantify and adopt EE optimised structural solutions.

The aim of this paper was to consider the latter of the above, by assessing potential structural design environmental efficiencies available through the use of alternate slab construction techniques. Environmental impacts were determined through EE analysis of numerous slab systems. Both Reinforced Concrete (RC) in-situ construction, as well as Post-Tensioned (PT) 
in-situ construction methods were investigated to establish any improvements available for the optimisation of environmental performance in structural designs.

\section{METHODOLOGY}

A multi-stage research methodology was formulated. This methodology was based on the methodology of previous research [40]. This study extended to include numerous other design variables and parameters such as slab systems, concrete strength, column to column spacing including various material and geometric parameters (Table 1). This research considered the environmental performance of buildings given set design criteria to simulate the practical limitations placed on structural engineers by architects and or clients. The external buildings dimensions were not considered adjustable under these design criteria. In order to assess the uniformity of environmental outcomes obtained using alternate slab design and construction techniques, two different building types were investigated. These have been detailed below as Case Study 1 and Case Study 2. An iterative design approach was conducted with the serviceability deflection limit requirements being the objective optimization parameter, delivering designs that adequately satisfy the requirements of AS3600-2009 with the most efficient material usage identified (Figure 1). This approach enabled structural system optimisation through the identification of deflection criteria governing overall slab thicknesses of all variations investigated. EE optimization occurred through minimising material usage requirements until allowable deflection limits were reached in accordance with AS3600-2009. Remaining structural design procedures in accordance with AS3600-2009 resulted in the structural design solutions provided. This methodology has been further detailed below. Cost factors were considered outside the scope of this research. 
The methodology was categorised into two major components, Structural Design and Environmental Analysis (Figure 1). The Structural Design involved several distinct components including: 1) Design Definition: formulation of design of the specific building to be analysed along with the identification of assumptions necessary to undertake the analysis. 2) Manual calculations were then undertaken in accordance with AS3600-2009 [52] to provide a detailed design of the structural element (slab), that was used for inputs into the two dimensional computer analysis program, RAPT; 3) The structural designs were finalised using the results obtained from the computer analysis. These were verified using comparison with manual calculations to ensure accuracy and suitability of the designs; 4) The structural requirements for each element were subsequently detailed allowing a bill of quantities (BOQ) to be generated and environmental performance assessment undertaken.

A number of structural design assumptions were identified for consistency and simplification of the assessment. These assumptions were:

- The slab has a constant span-depth ratio across all spans;

- Investigation did not consider lift core or tube system;

- Investigation did not consider lateral restraint systems;

- All designs use consistent reinforcement bar and tendon sizes (Table 1);

- Foundation requirements were omitted due to site specific requirements;

- Environmental assessment was included for structural elements only;

The study was conducted investigating two (2) separate structural types, in order to assess the consistency of results given different design criteria. These investigations were conducted under the following two (2) case studies to compare RC and PT environmental performance. 
Case Study 1) Investigate RC and PT flat plate slabs with various concrete strengths and column to column spacing, in a typical South-East Queensland concrete office structure (Figure 2);

Case Study 2) Investigate three different slab systems: flat plate, flat slab, and beam \& slab, reinforced by the means of either RC or PT construction (Figure 3).

The variation in dimension of each of these structures and the parameters investigated are detailed below.

2.1 Case Study 1- Investigate varying concrete strengths and column spacing in a typical concrete office structure

A typical South-East Queensland concrete office structure was investigated during this Case Study. This was a 10 story concrete building (Figure 2) based on the outcomes of previous research [40], with the results expanding on the knowledge obtained. For comparative purposes, designs were completed for a total of 64 separate slab systems, including each possible combination of: RC and PT construction, varying concrete strengths (32, 40, 50 and 65MPa) and clear span lengths (6.67, 8, 10 and 13.33m). A building footprint of fixed exterior $40.5 \times 40.5$ metres was adopted (Figure 2). This layout resulted in the analysis of the building containing 3-6 clear spans for the column spacing investigated. Typical flat plate slab construction system was used (Figure 3a), which was supported on a square grid of $500 \times 500 \mathrm{~mm}^{2}$ columns with $3.5 \mathrm{~m}$ floor to floor heights. Slabs were designed in accordance with all relevant Australian codes and standards. Due to the nature of the structure investigated, one (1) floor slab was designed per structure and multiplied by the number of levels to obtain material requirements. Roof slabs were designed independently to maximise material efficiencies. 
2.2 Case Study 2 - Investigate alternate slab systems of uniform plan dimension

Case Study 2 investigated slabs measuring $24.5 \times 33$ metres supported on a square grid of $500 \times 500 \mathrm{~mm}^{2}$ columns with $3.5 \mathrm{~m}$ floor to floor heights. Each end span was set at $8.0 \mathrm{~m}$, while interior spans measured $8.5 \mathrm{~m}$. This was an architectural decision due to end spans exhibiting higher overall deflection compared to interior spans, resulting in the need for either thicker slabs or shorter end spans, the latter of which was adopted (Figure 3). The only variations of these slabs (flat plate, flat slab, and beam \& slab) were the changes in material requirements due to different dimensions as a result of the alternate design methods being able to satisfactorily meet the design criteria. All slabs investigated during Case Study 2 were designed for 40MPa concrete.

The flat slab only differs from the flat plate by the additional drop panels over the columns. The panel dimensions are displayed (Figure 3b). The depth of these drop panels varies with normal slab depth (D) at a ratio of approximately 1.6D for both RC and PT slabs. The beam \& slab was chosen to have wide beams stretching in the longitudinal directions (Figure 3c). The beams have a width of $2.4 \mathrm{~m}$ internally and $1.2 \mathrm{~m}$ at the edges. Beams stretching in the latitudinal direction were added at the perimeter, with a width of $0.6 \mathrm{~m}$ (Figure 3c). This is usually done to create a nicer finish to the overall formwork. The depth of the beams varies with slab depth (D) just like the drop panels for the flat slab. For a RC beam \& slab the ratio for this depth was approximately 2.1D, while a PT slab, had a slightly smaller ratio of 1.75D.

\subsection{Design for strength and serviceability}

AS3600-2009 dictates that concrete structures shall be designed for both ultimate strength and serviceability limit state requirements in accordance with loading conditions specified in AS1170 [53] . All structures presented in this paper have been designed in accordance with 
these requirements. Office structures were investigated for the analysis due to the precise nature of loading conditions available in AS1170. All slabs were designed in accordance with the parameters summarised (Table 1). Deemed to comply span-to-depth ratio for RC slabs, were initially adopted as an initial indication of the required thickness for the RC slabs as detailed in Clause 9.3.4 [52]. The standard provides no simplified methods to determine the thickness of a PT slab. In large spans, it is more effective to use a span-depth ratio to determine the slab thickness. While various span-depth ratios are suggested in a number of published literature, those quoted by the Cement and Concrete Association of Australia Guide to Long Span Concrete Floors [54], were used. It is suggested that the most economical span-depth ratio, $\mathrm{L} / \mathrm{D}$, for a PT flat plate is between 37 and 40 [54]. After selection of an initial slab thickness based on these ratios and known span lengths for PT and RC slabs respectively, detailed design was conducted. This process progressively improved structural efficiencies until the most effective slab system was determined satisfying the minimum deflection limit requirements. The most efficient slabs display a minimum required thickness to control deflection and punching shear whilst maintaining acceptable reinforcement requirements. A minimum control over long-term deflection of $\frac{\Delta}{L_{e f}} \leq \frac{1}{250}$ was adopted for an office slab in compliance with Clause 2.3.2 [52]. In addition to this, a minimum control over incremental deflection of $\frac{\Delta}{L_{e f}} \leq \frac{1}{500}$ for all slabs was adopted. This deflection is critical in members supporting masonry partitions and brittle finishes which are present in most multi-storey office structures of this height. When calculating deflection, the elastic short-term deflection as well as long-term deflection caused by sustained load, or creep, and dry shrinkage were all taken into consideration as these heavily influence the magnitude of deflection experienced within a slab. During the structural design phase the objectives of the authors was to firstly present designs assessed in accordance with all relevant Australian Standards and secondly incorporate the iterative design approach 
presented, ensuring optimum design selection occurred in accordance with the criteria specified.

\subsection{Bill of Quantities}

For each of the slabs investigated during both Case Study 1 and 2, an extensive BOQ was required in order to compare and investigate the environmental performance of these structures. After detailed design, the BOQ was generated using each individual solution to the numerous structures investigated. The BOQ for each slab includes the concrete volume, unstressed reinforcement, prestressing strands, anchors and galvanised steel ducts as required for the designs. The BOQ detailed was those specified for the final slab design only and did not include any considerations for wastage or requirements for construction processors i.e. extra strand length for the PT jacking process.

\subsection{Embodied Energy}

Using the BOQ, an Environmental Impact Assessment (EIA) was undertaken using data obtained from the extensive literature review [30, 38, 55-59], to calculate an indicative value for the environmental impact of each structure in terms of EE. After extensive literature review, and previous research by the authors [40], the EE values published by Crawford [38] were used in this study (Table 2). While it is noted that high strength steel tendon fibres undergo different manufacturing procedures, there is significant limitations in current literature identifying suitably accurate values. No value is specified for EE of steel tendons in the study undertaken by Crawford [38]. In order to adopt an appropriate value, a conservative approach was taken in consultation with manufactures and the published literature, comparing other steel EE values. This value was estimated to be $50 \%$ greater than the detailed estimation of standard reinforcing bars calculated by Crawford [38] (Table 2). 


\section{RESULTS AND DISCUSSION}

\subsection{Embodied Energy Assessment - Case Study 1}

For the office structure investigated during Case Study 1 (Figure 2), material requirements as determined from the BOQ for each design were applied factors to quantify environmental performance (Table 2). All structural elements (excluding building fit-out) were included to determine structural material requirements. Results indicate a reduction in both floor and roof slab thicknesses are achieved through the implementation of PT construction methods. These reductions, when compared to RC slabs, range from $22 \%$ to $37 \%$ in floor slabs for the combinations of concrete strength and span length investigated (Table 3 \& Table 4). Similarly, roof slabs were observed to achieve reductions in thickness up to $37 \%$ through PT (Table $3 \&$ Table 4). It was also observed that reductions in thickness requirements occur for both floor and roof slabs with decreasing column-tocolumn spans. These reductions were consistent irrespective of the slab construction technique being utilised as expected (Table $3 \&$ Table 4).

With calculated variations in slab depths discussed, the required concrete volume reduced due to fixed building area. In addition to concrete reductions, PT slabs provided reduced steel requirements due to eccentricities offsetting loading conditions. Outcomes in relation to environmental performance have been prepared and presented in terms of overall EE of the structures investigated. The EE of each structure investigated during Case Study 1 was calculated (Figure 4). The use of PT reduced material requirements and therefore EE of the structure, when comparing only slab construction methods for all combinations investigated (Figure 4). It is evident that concrete strength, has little to no impact on the reduction in steel mass achievable when PT is used in comparison to RC (Table 3 \& Table 4). Span length variation impacted results significantly, in terms of EE outcomes, due to reduced steel mass 
requirements between $14 \%$ and $44 \%$ for the 4 spans investigated when comparing RC and PT construction (Table 3 \& Table 4). In the exception of the $6.67 \mathrm{~m}$ span, the reduction in steel mass increases with span length, which was also observed with concrete volume. This indicates that the usage of PT in structures with large spans is increasingly effective in minimizing relative material requirements. In the case of the $6.67 \mathrm{~m}$ span, it is apparent that a large reduction in steel mass was obtainable due to design reasons discussed in a previous study [60].

Total structural EE efficiencies were observed through the application of PT in comparison to RC. Environmental impacts in both PT and RC structures result mainly from concrete, contributing $51 \%$ to $63 \%$ of the EE. The greater contribution from concrete to overall structural mass (over 97\%) accounts for this majority whilst concurrently highlighting the disproportionate EE contribution of steel. Comparison of unit EE measures for steel and concrete, indicate the EE of steel being approximately 8-17 times that of concrete for the strengths investigated (Table 2). As a result, efficiency in its use achieves beneficial EE outcomes in comparison to minimising concrete material requirements. This is the balancing act that needs to be understood and constantly re-evaluated during a buildings design to ensure EE optimisation occurs. Environmental efficiencies achieved through both the material reductions of steel and concrete in the PT structure reveal reductions in total EE of the structures modelled between 28.1 and $40.9 \%$ (Figure 4). Construction material requirements also fell between $23 \%$ and $37 \%$ through the utilisation of PT construction methods (Table 3 \& Table 4).

Over all structures investigated during Case Study 1, variability in total EE consumed due to structural material requirements was extensive. For essentially the same structural system (excluding minor architectural variations), total results were between: the smallest EE, 38549.1GJ (PT, 6.67m Span, 32MPa) up to the largest EE 189475GJ (RC, 13.33m Span, 
65MPa) (Figure 4). This indicates an approximately five (5) times greater investment in EE across the structures investigated delivering an identical structural outcome.

\subsection{Embodied Energy Assessment - Case Study 2}

In accordance with Case Study 1, material requirements, determined from the BOQ generated for each design, were applied factors (Table 2), to quantify the environmental performance of the slabs investigated (Table 5). These BOQ were used to determine total EE for alternate slab construction techniques (Figure 3). Slabs failing the required code deflection requirements, were omitted for EE analysis (Table 5). EE optimisation was then conducted to determine the slabs meeting all design criteria achieving the lowest EE outcomes. The thinnest slab did not always equate to optimum EE performance. In the case of two (2) of the slabs chosen, this did not equal the thinnest slab option able to meet the design criteria. The PT flat plate and PT beam and slab, $200 \mathrm{~mm}$ and $140 \mathrm{~mm}$ or $160 \mathrm{~mm}$ deep slabs respectively satisfactorily completed the design criteria however resulted in larger EE outputs due to increased steel usage requirements. Results of this process have been presented (Figure 5). Results indicate a significant reduction in material requirements achieved through the implementation of PT construction methods, consistent with Case Study 1 . The selection of slab systems provides variation in the final EE efficiency of a slab for a given task. Comparative analysis between the most EE efficient RC vs PT options for all three (3) slab design methods observed reduced thicknesses for PT slabs in all cases, between $5 \%$ and $29 \%$ (Table 6). Over the three slab types investigated, total EE consumptions between 1412.57GJ (PT Flat Slab) and 3014.91GJ (RC Flat Plate) were observed. Comparisons have also been conducted between the same types of design system i.e. flat plate RC vs. flat plate PT etc. Results indicate that in all cases PT slab selection was more efficient in terms of EE with a reduction of between $23.7 \%$ and $49.1 \%$ (Table 6 \& Figure 5). Individual EE material 
contribution reductions of between $30.4 \%$ and $65.1 \%$ for steel (reinforcement + high tensile tendons in PT) as well as $13.7 \%$ and $29.0 \%$ for concrete were observed through the utilisation of PT slabs (Table 6).

For the EE assessment conducted during Case Study 1 and 2, optimization of this parameter was the sole focus. Under certain conditions increased investment in EE may be justified [38]. However it is worth noting that under current codes and legislation, there is no incentive for any stakeholder during the building procurement process to strive in optimizing EE results and environmental performance. Despite the extensive variability in EE of structures observed, its consideration in structural design remains ancillary to other factors [59]. Given the emergence of ZEB discussed [41-44], the significance of accurate assessment and optimization of EE cannot be overstated in the life cycle context. The optimization of EE in structures is unequivocally beneficial irrespective of the adoption rates of ZEB and the required technological developments. Positive adoption of ZEB results in increasingly beneficial environmental performance through the optimization of EE in structural design.

\subsection{Structural System Weight Variation - Case Study 1}

EE optimization has secondary benefits including structural system weight reductions. Any EE reductions are a result of direct material savings, achieved through the use of improved design methods. Structural system weights were calculated for all options investigated during this study. The structural building weights, of all alternatives investigated during Case Study 1, were determined with reductions between 19 and 37\% observed for PT vs RC construction. Average weight reductions in comparison between these structures were averaged between span lengths to evaluate a mean weight saving (Figure 6). Average weight reductions between $22.3 \%$ and $34.7 \%$ were observed for PT buildings. Total structural system weight for 
alternatives investigated during Case Study 1 varied between 9905 tonnes (PT 6.67m span, 65MPa) up to 36307 tonnes (RC 13.33m span, 32MPa) (Table 7).

\subsection{Structural System Weight Variation - Case Study 2}

Assessment of structural weight of slabs investigated during Case Study 2 was also undertaken. Results indicate structural weight savings for PT in comparison to RC construction, consistent with Case Study 1. For the slab completing the required design task, achieving the least EE consumptions (Table 6), structural weights were determined for comparison. Savings between $14.7 \%$ and $29.9 \%$ were determined (Figure 7 ). Total structural weight when comparing all possible design options ranged between 359 tonnes (PT Flat Slab) and 641 tonnes (RC Flat Plate) (Table 8). All structural system weights and savings are presented (Figure 7).

The results of both Case Study 1 and 2 highlight the importance of the contribution of steel to structures EE. The disproportionate contribution of steel to EE of a structure compared to its contribution to structural weight was investigated. Overall, for the structures investigated, steel accounts for between $1.51 \%$ and $3.92 \%$ (Table $7 \&$ Table 8 ) of the structure's weight but accounted for between: $28.1 \%$ and $49.0 \%$ of EE in Case Study 1 (Figure 4) and $40.8 \%$ and 59.6\% of EE in Case Study 2 (Figure 5). These outcomes highlight the importance of steel usage optimization for beneficial EE outcomes in concrete structural systems.

Reduced structural frame weight can result in additional benefits to other structural components, including: foundations, walls, and columns that contribute to the structure's overall EE. Therefore, the overall reduction in EE of the entire structure through the use of PT and its overall effectiveness may be equal to or higher than those presented here. These additional considerations were outside of the scope of this research but will be the focus of future investigations. 


\section{CONCLUSION}

The need for assessment methodologies was presented, with this analysis supplying one of the essential building blocks in achieving environmentally efficient structural design.

The results of this study will facilitate the improvement of the environmental efficiency of concrete buildings, to assist in instigating the need for national design codes and rating systems, targeting EE. By using an appropriate quantification technique and relative measure (EE), a comparison between different designs was conducted, enabling the presentation of EE efficiencies available using current knowledge and technology for a concrete structure.

The results obtained from this parametric study can be divided into two key components as determined from the structural design and subsequent environmental analysis. The findings are divided into material requirements of the structures and the associated EE consumptions. The findings obtained indicate a significant reduction in material requirements achieved through the implementation of PT construction methods. The use of PT is able to significantly reduce the concrete volume and more importantly in terms of EE, steel mass required for a structure. The variable results obtained from the selection of differing slab systems highlights the potential inefficiencies through the selection of an inappropriate system for any given application. Dissemination of these findings is important to increase the adoption of EE optimised structural systems.

Efficient structural systems will further result in overall building weight reductions leading to potential further material savings. From a practical perspective, the results of this study show that repetitive design favourites may not always lead to the most environmentally efficient structural system. 
Future research is proposed by the authors to advance the outcomes of this research. Previous research has identified reduced material efficiencies achievable through the use of alternate construction methods, however the quantification of this and incorporation of results into practicable, usable incentives by building stakeholders remained elusive. Preliminary investigations based on the outcomes of this work suggest, that despite the variability presented in EE outcomes of these structures, identical green building assessment scores would be obtained across all these structures. The authors intend to incorporate the quantifiable efficiencies presented, into green building assessment rating systems and further propose design methodologies through which sustainable structural optimisation becomes a primary consideration in all structural designs. Historically, the adoption of such issues has remained optional, however, future work plans to provide significant incentives to improve the adoption of such structural solutions.

\section{Acknowledgment}

Alliance Design Group (ADG) Consulting Engineers (www.adgce.com) has provided extensive support and resources to the development of this research topic. Through the past 5 years, ADG and its chairman Mr Tim Peters, have supplied technical and practical support through research associates and projects. The authors would like to acknowledge Mr Peters and his team for their efforts. Specifically the authors would like to acknowledge Mr Mitchell Mulvey, Mr Arvid Bergh and Ms Carmel Atkinson for their efforts and input into the development of this research. 


\section{REFERENCES}

1. International Union for Conservation of Nature and Natural Resources (IUCN), World Conservation Strategy. 1980, International Union for Conservation of Nature and Natural Resources (IUCN): Switzerland.

2. World Commission on Environment and Development (WCED), Our Common Future, G.H. Brundtland, Editor. 1987, United Nations General Assembly: New York. p. 374.

3. Intergovernmental Panel on Climate Change (IPCC), GEO 4: Environment for Development. 2007, United Nations Environment Programme (UNEP): Malta.

4. $\quad$ Lele, S.M., Sustainable Development: A Critical Review. World Develoment, 1991. 19(6): p. 607-621.

5. Mebratu, D., Sustainability and Sustainable Development: Historical and Conceptual Review. Environmental Impact Assessment, 1998. 18: p. 493-520.

6. Kates, R., Population and Consumption: What We Know, What We Need to Know. Environment, 2000. 42(3): p. 10-19.

7. Hasegawa, T., Environmentally Sustainable Buildings - Challenges and Polocies. 2003, (OECD) Organisation for Economic Co-Operation and Development: Frane. p. 194.

8. Smith, P.F., Architecture in a Climate of Change. 2nd Edn ed. 2005, Oxford: Architectural Press.

9. $\quad$ Asif, M., Muneer, T., and Kelley, R., Life Cycle Assessment: A Case study of a dwelling home in Scotland. Building and Environment, 2007. 42: p. 1391-1394.

10. Citherlet, S. and Defaux, T., Energy and environmental comparison of three variants of a family house during its whole life span. Building and Environment, 2007. 42(2): p. 591-598.

11. Wood, A., Sustainability: A New High-Rise Vernacular? The Structural Design of Tall and Special Buildings, 2007. 16: p. 401-410.

12. Dimoudi, A. and Tompa, C., Energy and environmental indicators related to construction of office buildings. Resources, Conservation and Recycling, 2008. 53(1-2): p. 86-95.

13. Stephan, A., Crawford, R.H., and Myttenaere, K.d., Towards a more holistic approach to reducing the energ demand of dwellings. Procedia Engineering, 2011. 21: p. 1033-1041.

14. Dixit, M.K., Fernández-Solís, J.L., Lavy, S., and Culp, C.H., Need for an embodied energy measurement protocol for buildings: A review paper. Renewable and Sustainable Energy Reviews, 2012. 16(6): p. 3730-3743.

15. Langston, Y.L. and Langston, C.A., Reliability of building embodied energy modelling: an analysis of 30 Melbourne case studies. Construction Management and Economics, 2013. 26: p. 147-160. 
16. Baek, C., Park, S.-H., Suzuki, M., and Lee, S.-H., Life cycle carbon dioxide assessment tool for buildings in the schematic design phase. Energy and Buildings, 2013. 61: p. 275-287.

17. Schokker, A.J., The Sustainable Concrete Guide: Strategies and Examples. First Edition ed, ed. U.S.G.C. Council. 2010, Michigan: U.S. Green Concrete Council

18. World Business Council for Sustainable Development (WBCSD), Cement Industry Energy and CO2 Performance: Getting the Numbers Right. 2006, World Business Council for Sustainable Development,, (WBCSD): Geneva.

19. Flower, D.J.M. and Sanjayan, J.G., Green house gas emissions due to concrete manufacture. The International Journal of Life Cycle Assessment, 2007. 12(5): p. 282-288.

20. Walker-Morison, A., Grant, T., and McAlister, S., The Environmental Impact of Building Materials. Environment Design Guide, 2007. PRO 7.

21. Lippiatt, B.C., Selecting Cost Effective Green Building Products: BEES Approach. Journal of Construction Engineering and Management, 1999. 125: p. 448-455.

22. Chong, W.K., Kumar, S., Haas, C.T., Beheiry, S.M.A., Coplen, L., and Oey, M., Understanding and Interpreting Baseline Perceptions of Sustainability in Construction among Civil Engineers in the United States. Journal of Management in Engineering, 2009. 25(3): p. 143-154.

23. O'Riordan, T., Future directions in environmental policy. Journal of Environment and Planning, 1985. 17: p. 1431-1446.

24. Redclift, M., Sustainable Development: Exporing the Contradictions. 1987, New York: Methuen.

25. Goldin, I. and Winters, L.A., The Economics of Sustainable Development. 1995, Cambridge: University of Cambridge Press.

26. Tryzna, T.C., A Sustainable World. 1995, International Union for Conservation of Nature and Natural Resources (IUCN): Sacremento.

27. Kates, R., Parris, T., and Leiserowitz, A., What Is Sustainable Development? Goals, Indicators, Values and Practice. Environment: Science and Policy for Sustainable Development, 2005. 47(3): p. 8-21.

28. Spreckley, F., Social Audit: A Management Tool for Co-operative Working. 1981, Leeds: Beechwood College Ltd. 45.

29. Adams, W.M., The Future of Sustainability: Re-thinking Environment and Development in the Twenty-first Century. 2006, (IUCN) The World Conservation Union.

30. Miller, D., Doh, J.-H., and Guan, H. Environmentally Efficient and Sustainable Design Methodology of Concrete Residential and Office Buildings: A Review. in The 2011 International Conference on Advances in Structural Engineering and Mechanics. 2011. Seoul, Korea.

31. Miller, D., Doh, J.-H., and Peters, T., Optimised design selection and environmental impact assessment of alternate slab construction methods, in The 2013 World Congress on Advances in Structural Engineering and Mechanics, C.K. Choi, Editor. 2013: Jeju, Korea. 
32. European Union (EU), An Agenda For Sustainable Construction in Europe. 2001: Brussels. p. 65.

33. Australian Bureau of Statistics (ABS). 1350.0 A Statistical Review of the Construction Industry. 2010 28th October 2010 [cited 2013 12th November]; Available from:

http://www.abs.gov.au/AUSSTATS/abs@.nsf/Lookup/1350.0Feature+Article1Oct +2010 .

34. Cement, Concrete \& Aggregates Australia, (CCAA) Sustainable Concrete Buildings. 2010, Cement, Concrete \& Aggregates Australia: Sydney. p. 8.

35. Omar, W.M.S.W., Doh, J.-H., Panuwatwanich, K., and Miller, D., Assessment of the embodied carbon in precast concrete wall panels using a hybrid life cycle assessment approach in Malaysia. Sustainable Cities and Society, 2013. 10: p. 111.

36. Cole, R.J. and Kernan, P.C., Life-Cycle Energy Use in Office Buildings. Building and Environment, 1996. 31(4): p. 307-317.

37. Commonwealth of Australia, (CoA), Scoping Study to Investigate Measures for Improving the Environmental Sustainability of Building Materials. 2006: Canberra.

38. Crawford, R.H., Life Cycle Assessment in the Built Environment. 2011, London: Taylor and Francis.

39. Yeo, D. and Gabbai, R.D., Sustainable design of reinforced concrete structures through embodied energy optimization. Energy and Buildings, 2011. 43(2011): p. 2028-2033.

40. Miller, D. and Doh, J.-H., Incorporating sustainable development principles into building design: a review from a structural perspective including case study. The Structural Design of Tall and Special Buildings, 2014: p. n/a-n/a.

41. Crawford, R.H., Towards a comprehensive approach to zero-emissions housing. Architectural Science Review, 2011. 54(4): p. 277-284.

42. Marszal, A.J. and Heiselberg, P., Life cycle cost analysis of a multi-storey residential Net Zero Energy Building in Denmark. Energy, 2011. 36(9): p. 56005609.

43. Monahan, J. and Powell, J.C., A comparison of the energy and carbon implications of new systems of energy provision in new build housing in the UK. Energy Policy, 2011. 39(1): p. 290-298.

44. Zuo, J., Read, B., Pullen, S., and Shi, Q., Achieving carbon neutrality in commercial building developments - Perceptions of the construction industry. Habitat International, 2012. 36(2): p. 278-286.

45. Cole, R.J., Energy and Greenhouse Gas Emissions Associated with the Construction of Alternative Structural Systems. Building and Environment, 1999. 34: p. 335-348.

46. Treloar, G.J., Fay, R., Love, P., and Iyer-Raniga, U., Analysing the life-cycle energy of an Australian residential building and its householders. Building Research and Information, 2000. 28(3): p. 184-195. 
47. Fay, R., Treloar, G., and Iyer-Raniga, U., Life-cycle energy analysis of buildings: a case study. Building Research \& Information, 2000. 28(1): p. 31-41.

48. Greene, D., Green Building. Environment Design Guide, 2005. DES 25.

49. Adalberth, K., Energy Use during the Life Cycles of Single Unit Dwellings: Examples. Building and Environment, 1997. 32(4): p. 321-329.

50. Mithraratne, N. and Vale, B., Life cycle analysis model for New Zealand houses. Building and Environment, 2004. 39(4): p. 483-492.

51. Thormark, C., A low energy building in a life cycle - its embodied energy, energy need for operationand recycling potential. Building and Environment, 2002. 37: p. 429-435.

52. Standards Association of Australia (SAA), Australian Standard: Concrete Structures, in AS3600-2009. 2010, Standards Australia International: Sydney.

53. Standards Association of Australia (SAA), AS1170.0 Structural Design Actions. 2002, Standards Association of Australia, : Sydney.

54. Cement and Concrete Association of Australia (CCAA), Guide to Long-Span Concrete Floors. 2003: TechMedia Publishing Pty Ltd.

55. Lawson, B., Embodied Energy of Building Materials. Environment Design Guide, 2000. PRO 2.

56. Treloar, G.J., Fay, R., Ilozor, B., and Love, P., An Analysis of the Embodied Energy of Office Buildings by Height. Facilities, 2001. 19(5): p. 204-214.

57. Norgate, T.E. and Rankin, W.J., The role of Metals in Sustainable Development, in The International Conference on the Sustainable Processing of Minerals. 2002:

Cairns.

58. Aye, L., Ngo, T., Crawford, R.H., Gammampila, R., and Mendis, P., Life cycle greenhouse gas emissions and energy analysis of prefabricated reusable building modules. Energy and Buildings, 2011. 47(April 2012): p. 159-168.

59. Miller, D., Doh, J.-H., and Peters, T., Environmental Impact Assessment of Post Tensioned and Conventional Reinforced Concrete Structures, in The 7th International Structural Engineering and Construction Conference, S. Yazdani and A. Singh, Editors. 2013: Honolulu, Hawaii.

60. Miller, D., Doh, J.-H., Guan, H., Mulvey, M., Fragomeni, S., McCarthy, T., and Peters, T., Environmental Impact Assessment of Post-Tensioned and Reinfirced Concrete Slab Construction, in 22nd Australasian Conference on the Mechanics of Structures and Materials ACMSM 22. 2012: Sydney. 